This article has been updated from its originally published version to correct errors in text and update Figs. 2-4. See the corresponding erratum notice, DOI: 10.3171/2015.3.PEDS14326a.

J Neurosurg Pediatrics (Suppl) 14:44-52, 2014

(C)AANS, 2014

\title{
Pediatric hydrocephalus: systematic literature review and evidence-based guidelines. Part 6: Preoperative antibiotics for shunt surgery in children with hydrocephalus: a systematic review and meta-analysis
}

\author{
Paul Klimo JR., M.D., M.P.H., ${ }^{1-3}$ Mark Van PopPel, M.D., ${ }^{2,3}$ \\ Clinton J. Thompson, Ph.D., ${ }^{5}$ Lissa C. Baird, M.D., ${ }^{4}$ Ann-Christine Duhaime, M.D. ${ }^{6}$ \\ AND Ann Marie Flannery, M.D.?
}

\begin{abstract}
${ }^{1}$ Semmes-Murphey Neurologic \& Spine Institute; ${ }^{2}$ Department of Neurosurgery, University of Tennessee Health Science Center; and ${ }^{3}$ Le Bonheur Children's Hospital, Memphis, Tennessee; ${ }^{4}$ Department of Neurological Surgery, Oregon Health \& Science University, Portland, Oregon; ${ }^{5}$ School of Public Health and Health Services, The George Washington University, Washington, DC; ${ }^{6}$ Department of Pediatric Neurosurgery, Massachusetts General Hospital, Boston, Massachusetts; and ${ }^{7}$ Department of Neurological Surgery, Saint Louis University, St. Louis, Missouri
\end{abstract}

Object. The objective of this systematic review and meta-analysis was twofold: to answer the question "What is the evidence for the effectiveness of prophylactic intravenous antibiotics for infection prevention in shunt surgery?" and to make treatment recommendations based on the available evidence.

Methods. The US National Library of Medicine PubMed/MEDLINE database and the Cochrane Database of Systematic Reviews were queried using MeSH headings and key words relevant to prophylactic antibiotic use in children undergoing a shunt operation. Abstracts were reviewed to identify which studies met the inclusion criteria. An evidentiary table was assembled summarizing the studies and the quality of evidence (Classes I-III). A meta-analysis was conducted using a random-effects model to calculate a cumulative estimate of treatment effect using risk ratio (RR). Heterogeneity was assessed using chi-square and $\mathrm{I}^{2}$ statistics. A sensitivity analysis was also conducted. Based on the quality of the literature and the result of the meta-analysis, a recommendation was rendered (Level I, II, or III).

Results. Nine studies (4 Class I, 3 Class II, and 2 Class III) met our inclusion criteria. Of 7 randomized controlled trials (RCTs), 3 were downgraded from Class I to Class II because of significant quality issues, and all RCTs were potentially underpowered. In only 2 Class III retrospective cohort studies were preoperative antibiotic agents found to be protective against shunt infection. When data from the individual studies were pooled together, the infection rate in the prophylactic antibiotics group was $5.9 \%$ compared with $10.7 \%$ in the control group. Using a random-effects model, the cumulative RR was 0.55 (95\% CI 0.38-0.81), indicating a protective benefit of prophylactic preoperative intravenous antibiotics. A sensitivity analysis of RCTs only $(n=7)$ also demonstrated a statistical benefit, but an analysis of higher-quality RCTs only $(n=4)$ did not.

Conclusions. Within the limits of this systematic review and meta-analysis, administration of preoperative antibiotic agents for shunt surgery in children was found to lower the infection risk (quality of evidence: Class II; strength of recommendation, Level II).

RECOMMENDATION: The use of preoperative antibiotic agents can be recommended to prevent shunt infection in patients with hydrocephalus. It was only by combining the results of the various underpowered studies (metaanalysis) that the use of preoperative antibiotics for shunt surgery in children was shown to lower the risk of shunt infection. StRENGTH of ReCOMMENDATION: Level II, moderate degree of clinical certainty.

(http://thejns.org/doi/abs/10.3171/2014.7.PEDS14326)

$\begin{aligned} & \text { KEY WORDS } \\ & \text { shunt } \bullet \text { preoperative } \\ & \text { evidence-based guidelines }\end{aligned} \underbrace{\bullet}_{\text {practice guidelines }} \begin{gathered}\text { perioperative } \\ \text { heta-analysis } \\ \text { hydrocephalus }\end{gathered}$

Abbreviations used in this paper: AANS = American Association of Neurological Surgeons; CNS = Congress of Neurological Surgeons; RCT = randomized controlled trial; RR = risk ratio; VP $=$ ventriculoperitoneal.
$\mathrm{C}$ EREBROSPINAL fluid shunting procedures are among the most common procedures performed by pediatric neurosurgeons, but infection remains a challenging complication to prevent. Care of patients with infected shunts often requires prolonged hospitalization, 
long-term intravenous antibiotic administration, and multiple surgical procedures; therefore, it comes as no surprise that shunt infections are among the most expensive implant-related complications to treat, with an annual estimated total cost of \$100-250 million., , $15,35^{\text {The clinical }}$ consequences of a shunt infection include seizures, psychomotor retardation, reduced intelligence quotient, and increased mortality. $13,22,25,32,37,39$

The rate of shunt infection reported varies considerably in the literature, but in recent studies the incidence typically ranges from $5 \%$ to $15 \%$, with rates typically higher in high-risk groups such as preterm neonates and patients recently treated for shunt infection. $28,33,34,36,42$ Evidence of a shunt infection often manifests within 2 months after surgery. Infections are typically caused by gram-positive opportunistic pathogens that colonize the skin of the patient such as coagulase-negative Staphylococcus, S. epidermidis, and S. aureus. ${ }^{28}$

The administration of preoperative antibiotic agents, typically those providing gram-positive coverage such as a first-generation cephalosporin, nafcillin, clindamycin, or vancomycin, has been demonstrated or is assumed to lower the infection rate for all major cranial and spinal neurosurgical procedures. ${ }^{4-6}$ Numerous studies, including 3 meta-analyses, ${ }^{21,24,29}$ have investigated the use of preoperative antibiotics as prophylaxis against shunt infection, both for adult and pediatric patients. Many of the original trials date back to the 1980s, and it is one of the few areas in neurosurgery in which there is an abundance of randomized controlled trials (RCTs).

Currently, the use of prophylactic antibiotics for shunt surgery is almost ubiquitous but not uniform. Biyani et al. ${ }^{9}$ conducted a survey study in which they asked pediatric neurosurgeons to detail their use of prophylactic antibiotics. All 45 respondents indicated that they used antibiotics; however, there was notable variability in the choice of drug (first-generation cephalosporins [ $\mathrm{n}=23$ ], second-generation cephalosporins [ $\mathrm{n}=10]$, naficillin/oxacillin $[n=4]$, vancomycin $[n=3]$, clindamycin $[n=1]$, amoxicillin $[n=1]$, or mixed protocols $[n=3]$ ); the timing of drug delivery (in the department before transfer to the operating room $[n=5]$, upon arrival at the operating room [n $=11]$, at induction of anesthesia [n = 13], or at initial skin incision $[n=16]$ ); and the duration of drug delivery (single dose $[\mathrm{n}=13], 24$-hour administration [ $\mathrm{n}$ = 26], 48-hour administration [ $\mathrm{n}=2$ ], or administration longer than 48 hours $[n=4])$. Surgeons also tended to modify their protocols for certain "high-risk" patients.

The purpose of this evidence-based review is to critically examine data on the use of preoperative prophylactic antibiotics in children undergoing shunt surgery.

\section{Methods}

\section{Search Terms}

We searched the US National Library of Medicine PubMed/MEDLINE database and the Cochrane Database of Systematic Reviews for the period from January 1966 to March 2012 using the MeSH subject headings and the following PubMed search terms: 1. ("Cerebrospi- nal Fluid Shunts"[MeSH] OR "shunt systems" OR ("cerebrospinal fluid" AND (shunt* OR catheter*))); and then 1 AND (infection OR infections OR "shunt infection") AND ("Anti-Bacterial Agents"[MeSH] OR (antibiotic OR antibiotics)) AND (prophylaxis OR prevention OR protective).

\section{Search Strategy}

We reviewed the retrieved articles's titles and abstracts to identify studies addressing the rate of shunt infection in patients treated with preoperative antibiotic agents compared with those treated with no prophylaxis. Uncontrolled studies were excluded, as were studies that evaluated intrathecal antibiotics. In all papers, the authors must have stated that the only variable that changed was the administration of perioperative antibiotics; all other aspects of the surgery and technique remained unchanged. In addition, the authors must have provided details regarding their prophylaxis protocol-drug(s), dosage, and timing of administration before and, if applicable, after surgery.

\section{Meta-Analysis}

For each study, we identified the number of infections in the group of patients who were treated by antibiotics as well as in the group of patients who did not receive prophylactic antibiotics (control group). We then computed the risk of an infection for the treatment group relative to the control group, yielding a risk ratio (RR). An RR less than 1 is indicative of protection against infection for prophylactic antibiotics. The overall RR was computed using the method of DerSimonian and Laird. ${ }^{17}$

We conducted a random-effects meta-analysis of the selected studies. A random-effects model-as opposed to a fixed-effects model-assumes the measure of association (that is, the RR) varies around an overall average treatment effect. A random-effects model yields a more conservative estimate of the summary effect. We assessed heterogeneity by way of the chi-square test of heterogeneity and the $\mathrm{I}^{2}$ statistic, in which the former returns a chi-square distributed test statistic and corresponding $\mathrm{p}$ value and the latter returns a value bound between $0 \%$ and $100 \%$, with higher values denoting increasing heterogeneity. We regarded a chi-square test of heterogeneity $p$ value less than alpha $=0.10$ and an $\mathrm{I}^{2}$ value in the range of $30 \%$ to $60 \%$ as suggestive of moderate heterogeneity. ${ }^{14,16}$

We performed a sensitivity analysis by repeating the meta-analysis using only RCTs and then further by examining only the higher-quality RCTs. An examination of publication bias was not conducted, because the number of studies included in this analysis was not large enough to provide adequate power (i.e., fewer than 10 studies).

\section{Search Results}

Our search identified 177 articles; another 7 articles were found through a search of the articles' bibliographies (Fig. 1). One hundred sixty-two articles were excluded based on a review of the abstract. Twenty-two full-length papers were reviewed, of which 13 were rejected for the following reasons: studies either enrolled only adults or 


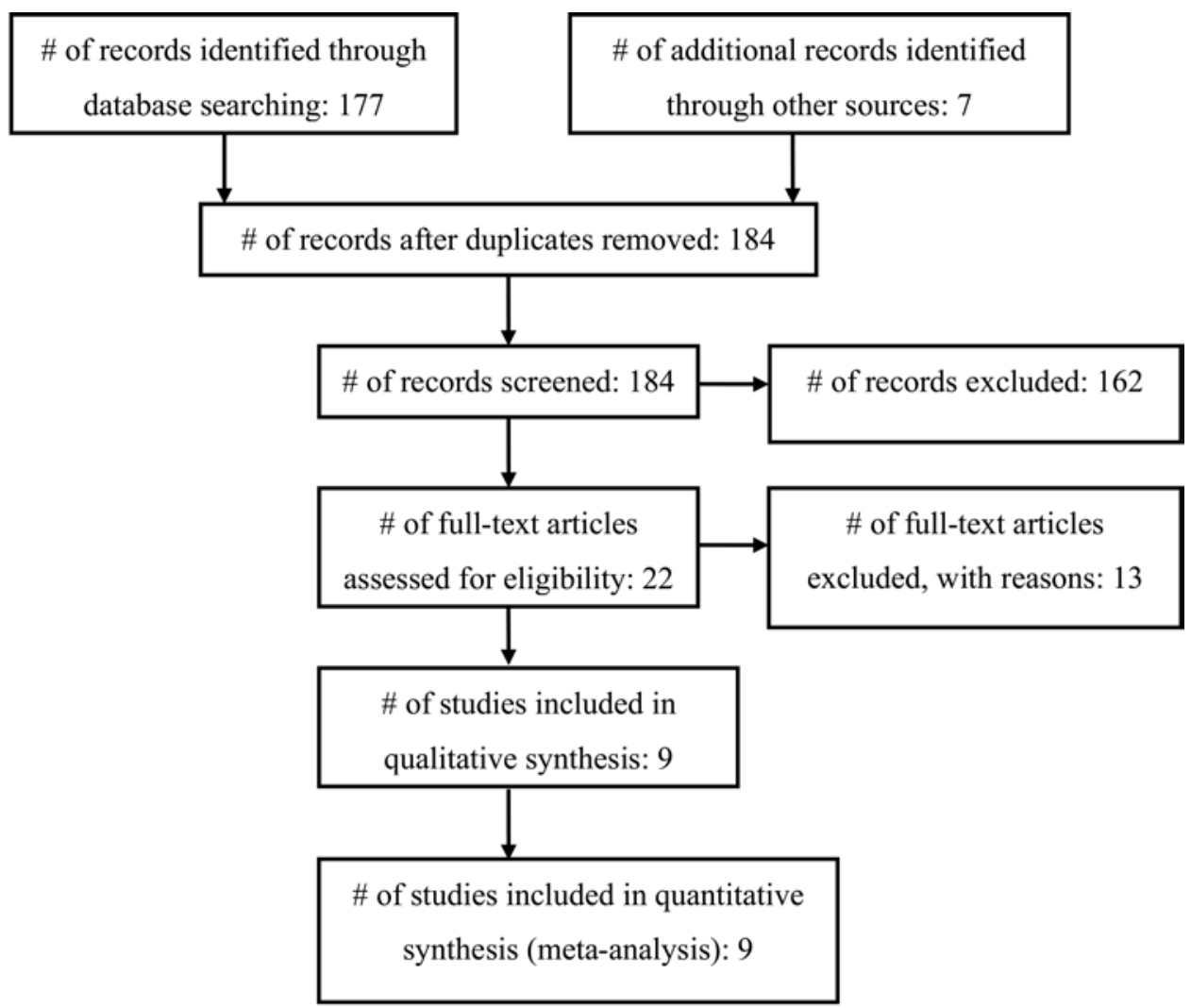

Fig. 1. Flowchart showing the selection of studies for inclusion in the review and meta-analysis.

separate results for children were not provided; $;, 10,19,31,41$ there was no comparison group; ${ }^{2}$ prophylactic antibiotic use was part of a shunt surgery protocol, and thus more than one variable was conceivably being altered; 23,38 clinical shunt infection was not used as the outcome; ${ }^{7}$ no details regarding the prophylaxis used were provided; ${ }^{32}$ a variety of antibiotics was used (that is, there was no standardization of the prophylaxis protocol),${ }^{44}$ or data specific to shunt surgery were not available. ${ }^{12,43}$ Therefore, 9 articles satisfied inclusion criteria for this systematic review and meta-analysis (Table 1). 1,11,18,20,26,27,30,39,40

\section{Results}

The review process identified 4 Class I, 3 Class II, and 2 Class III studies. Seven of the 9 papers described RCTs, but there were notable methodological shortcomings and incomplete studies as detailed below. The primary outcome of interest-shunt infection-was defined by the authors of the individual studies but in general included signs and symptoms of a shunt malfunction or infection with an organism cultured from the CSF or shunt apparatus, purulence from the shunt wound(s), or abdominal fluid/pseudocyst in a patient after a recent shunt surgery. Some investigators also deemed that a patient had an infection if there were highly suggestive findings such as fever, redness along the shunt, or CSF pleocytosis in the absence of positive cultures. Among the studies, there was variability in which antibiotics were tested, their administration relative to the skin incision, and whether the patient received postoperative antibiotics. The only constant feature was that the children in the study groups all received preoperative antibiotics of some kind and at some time interval prior to skin incision. Overall, only 2 studies found that preoperative antibiotics were protective against shunt infection.

Seven RCTs met our inclusion criteria, but 3 of these were downgraded to Class II quality because of serious flaws, typically lack of information about issues such as blinding, randomization sequence generation, and allocation concealment. ${ }^{11,18,27}$ The trial by Blum et al. ${ }^{11}$ showed no difference in the infection rate with a relatively small number of patients. The treatment group consisted of 50 patients who received preoperative cefazedone $(50 \mathrm{mg} / \mathrm{kg}$ at the time of induction). The trial had significant flaws, specifically: follow-up was limited to only 8 weeks; the randomization sequence was poor (based on the patient's date of birth); there was no attempt at blinding or allocation concealment; and although the authors mentioned "placebo" in the introduction, no details of it were provided in the methods. The trial by Djindjian et al. ${ }^{18}$ was also poorly reported, and thus we downgraded it to a Class II study. Oxacillin was administered at a dose of $200 \mathrm{mg} /$ $\mathrm{kg}$ /day beginning with induction and completing 6 doses in 24 hours. Only 19 of the 60 patients were subcategorized into an age group of younger than 6 years of age, which qualified for our analysis. The infection rate in the 
Part 6: Preoperative antibiotics for shunt surgery

TABLE 1: Preoperative antibiotics: summary of evidence

\begin{tabular}{|c|c|c|c|}
\hline $\begin{array}{l}\text { Authors \& } \\
\quad \text { Year }\end{array}$ & Study Description & $\begin{array}{l}\text { Data Class, } \\
\text { Quality, \& Reasons }\end{array}$ & Results \& Conclusions \\
\hline $\begin{array}{l}\text { Walters et } \\
\text { al., } 1992\end{array}$ & $\begin{array}{l}20 \mathrm{mg} / \mathrm{kg} \text { rifampin \& } 5 \mathrm{mg} / \mathrm{kg} \text { trime- } \\
\text { thoprim given orally } 2 \mathrm{hrs} \text { preop, } 8 \mathrm{hrs} \\
\text { postop, \& again every } 8 \mathrm{hrs} \text { for } 48 \mathrm{hrs} \text {. }\end{array}$ & $\begin{array}{l}\text { Class I } \\
\text { RCT, double-blinded, placebo given. }\end{array}$ & $\begin{array}{l}\text { Treatment Group: } 14 \text { of } 155(9 \%) \text {; Control } \\
\text { Group: } 22 \text { of } 145(15 \%) \text {. No statistically } \\
\text { significant difference. Trial terminated } \\
\text { early because of a higher than antici- } \\
\text { pated infection rate in both groups. }\end{array}$ \\
\hline $\begin{array}{l}\text { Wang et al., } \\
\quad 1984\end{array}$ & $\begin{array}{l}25 \mathrm{mg} / \mathrm{kg} \text { sulfamethoxazole } \& 5 \mathrm{mg} / \\
\mathrm{kg} \text { trimethoprim given w/in } 1 \mathrm{hr} \text { of } \\
\text { surgery \& } 8 \text { \& } 16 \text { hrs postoperatively. }\end{array}$ & $\begin{array}{l}\text { Class I } \\
\text { RCT, double-blinded, placebo given. }\end{array}$ & $\begin{array}{l}\text { Treatment Group: } 4 \text { of } 55 \text { (7.3\%); Control } \\
\text { Group: } 5 \text { of } 65 \text { (7.7\%). No statistically } \\
\text { significant difference. }\end{array}$ \\
\hline $\begin{array}{l}\text { Rieder et al., } \\
1987\end{array}$ & $\begin{array}{l}25 \mathrm{mg} / \mathrm{kg} \text { cephalothin given in operating } \\
\text { room before incision \& } 3 \text { times postop, } \\
\text { once every } 6 \text { hrs. }\end{array}$ & $\begin{array}{l}\text { Class I } \\
\text { RCT, double-blinded, placebo given. }\end{array}$ & $\begin{array}{l}\text { Treatment Group: } 2 \text { of } 32 \text { (6\%); Control } \\
\text { Group: } 3 \text { of } 31(10 \%) \text {. No statistically } \\
\text { significant difference. }\end{array}$ \\
\hline $\begin{array}{l}\text { Haines \& } \\
\text { Taylor, } \\
1982\end{array}$ & $\begin{array}{l}12.5 \mathrm{mg} / \mathrm{kg} \text { methicillin every } 6 \mathrm{hrs} \text { begin- } \\
\text { ning } 6 \mathrm{hrs} \text { before surgery, at induction } \\
\text { of anesthesia, \& up to } 72 \mathrm{hrs} \text { postop. }\end{array}$ & $\begin{array}{l}\text { Class I } \\
\text { RCT, no indication of blinding, placebo given. }\end{array}$ & $\begin{array}{l}\text { Treatment Group: } 2 \text { of } 35 \text { (5.7\%); Control } \\
\text { Group: } 5 \text { of } 39 \text { (12.8\%). No statistically } \\
\text { significant difference. }\end{array}$ \\
\hline $\begin{array}{l}\text { Blum et al., } \\
\qquad 1989\end{array}$ & $\begin{array}{l}50 \mathrm{mg} / \mathrm{kg} \text { cefazedone given at time of } \\
\text { induction. }\end{array}$ & $\begin{array}{l}\text { Class II } \\
\text { RCT, single-blinded, use of placebo mentioned } \\
\text { in introduction, but no details provided in } \\
\text { methods. Significant flaws in sequence } \\
\text { generation \& allocation concealment. }\end{array}$ & $\begin{array}{l}\text { Treatment Group: } 3 \text { of } 50(6 \%) \text {; Control } \\
\text { Group: } 7 \text { of } 50(14 \%) \text {. No statistically } \\
\text { significant difference. }\end{array}$ \\
\hline $\begin{array}{l}\text { Djindjian et } \\
\quad \text { al., } 1986\end{array}$ & $\begin{array}{l}200 \mathrm{mg} / \mathrm{kg} / \text { day oxacillin for a total of } 6 \\
\text { doses ( } 24 \mathrm{hrs} \text { ), } 1 \text { st dose given upon } \\
\text { insertion of intravenous therapy in } \\
\text { operating room. }\end{array}$ & $\begin{array}{l}\text { Class II } \\
\text { RCT, but no methodology details provided by } \\
\text { authors such as sequence generation, al- } \\
\text { location concealment, blinding, etc. }\end{array}$ & $\begin{array}{l}\text { Treatment Group: } 1 \text { of } 9(11 \%) \text {; Control } \\
\text { Group: } 1 \text { of } 10(10 \%) \text {. No statistically } \\
\text { significant difference. }\end{array}$ \\
\hline $\begin{array}{l}\text { Odio et al., } \\
\quad 1984\end{array}$ & $\begin{array}{l}15 \mathrm{mg} / \mathrm{kg} \text { vancomycin hydrochloride } 1 \mathrm{hr} \\
\text { before surgery \& again } 6 \text { hrs later. }\end{array}$ & $\begin{array}{l}\text { Class II } \\
\text { RCT, double-blinded, placebo given, but no } \\
\text { methodology details provided by authors } \\
\text { such as sequence generation, allocation } \\
\text { concealment, blinding, etc. }\end{array}$ & $\begin{array}{l}\text { Treatment Group: } 3 \text { of } 18 \text { (17\%); Control } \\
\text { Group: } 4 \text { of } 17(24 \%) \text {. No statistically } \\
\text { significant difference. Trial terminated } \\
\text { early because of adverse reactions to } \\
\text { vancomycin. }\end{array}$ \\
\hline $\begin{array}{l}\text { Ajir et al., } \\
1981\end{array}$ & $\begin{array}{l}50 \mathrm{mg} / \mathrm{kg} \text { methicillin given in operating } \\
\text { room before incision. }\end{array}$ & $\begin{array}{l}\text { Class III } \\
\text { Retrospective cohort. }\end{array}$ & $\begin{array}{l}\text { Treatment Group: } 3 \text { of } 66 \text { ( } 4.5 \%) \text {; Control } \\
\text { Group: } 8 \text { of } 105(7.6 \%) \text {. Preoperative } \\
\text { antibiotics were protective against } \\
\text { infection. }\end{array}$ \\
\hline $\begin{array}{l}\text { McCullough } \\
\text { et al., } \\
1980\end{array}$ & $\begin{array}{l}25 \mathrm{mg} / \mathrm{kg} \text { methicillin given immediately } \\
\text { before transport to operating room, } \\
1 \text { dose after exposing the shunt or } \\
\text { cannulating the ventricle, \& } 6 \text { postop } \\
\text { doses given every } 6 \text { hrs. }\end{array}$ & $\begin{array}{l}\text { Class III } \\
\text { Retrospective cohort. }\end{array}$ & $\begin{array}{l}\text { Treatment Group: } 6 \text { of } 223(2.7 \%) \text {; Con- } \\
\text { trol Group: } 17 \text { of } 212(8 \%) \text {. Preopera- } \\
\text { tive antibiotics were protective against } \\
\text { infection. }\end{array}$ \\
\hline
\end{tabular}

treatment group was $11 \%$ (1 of 9), compared with $10 \%$ (1 of 10) in the control group.

Two trials were terminated prematurely. ${ }^{27,39}$ Odio et al. ${ }^{27}$ stopped their trial early because of adverse drug reactions. The authors also failed to provide important details on their methodology; thus we downgraded the trial to Class II. The trial was a multiinstitution double-blind placebo-controlled study. Vancomycin hydrochloride (15 $\mathrm{mg} / \mathrm{kg}$ ) was given as a 60-minute intravenous infusion approximately 1 hour before surgery and again 6 hours later. In infants younger than 7 days of age, the interval between doses was 12 hours. Follow-up was 7-12 months after surgery. Only 37 patients were enrolled, 20 in the vancomycin group and 17 in the placebo group. The authors excluded 2 patients from the analysis because they received only 1 dose of vancomycin hydrochloride (there were adverse reactions to the first dose). Overall, the infection rates were $17 \%$ ( 3 of 18) and $24 \%$ ( 4 of 17 patients) for the vancomycin and placebo groups, respectively. The trial was stopped early because adverse reactions to vancomycin were observed in 7 (35\%) of 20 patients.

Walters et al. ${ }^{39}$ conducted a randomized, doubleblind, placebo-controlled trial of perioperative oral rifampin-trimethoprim antibiotic treatment $(20 \mathrm{mg} / \mathrm{kg}$ rifampin and $5 \mathrm{mg} / \mathrm{kg}$ trimethoprim given 2 hours preoperatively, 8 hours postoperatively, and again every 8 hours for 48 hours) in 243 patients who underwent 300 CSF shunting procedures. Patients were stratified into one of 4 groups: de novo shunt insertions in patients without spina bifida, de novo shunt insertions in patients with spina bifida, shunt revisions in patients previously enrolled in the trial, and shunt revisions in patients who had not been pre- 


\begin{tabular}{|c|c|c|c|c|}
\hline $\begin{array}{l}\text { Author } \\
\text { (year) }\end{array}$ & $\mathrm{RR}(95 \% \mathrm{Cl})$ & $\begin{array}{l}\text { Events, } \\
\text { Treatment }\end{array}$ & $\begin{array}{l}\text { Events, } \\
\text { Control }\end{array}$ & $\begin{array}{l}\% \\
\text { Weight }\end{array}$ \\
\hline Walters et al (1992) & $0.60(0.32,1.12)$ & $14 / 155$ & $22 / 145$ & 36.01 \\
\hline Wang et al (1984) & $0.95(0.27,3.35)$ & $4 / 55$ & $5 / 65$ & 8.95 \\
\hline Rieder et al (1987) & $0.65(0.12,3.61)$ & $2 / 32$ & $3 / 31$ & 4.84 \\
\hline Ajir et al (1981) & $0.60(0.16,2.17)$ & $3 / 66$ & $8 / 105$ & 8.60 \\
\hline Blum et al (1989) & $0.43(0.12,1.56)$ & $3 / 50$ & $7 / 50$ & 8.55 \\
\hline Djindjian et al (1986) & $1.11(0.08,15.28)$ & $1 / 9$ & $1 / 10$ & 2.08 \\
\hline McCullough et al (1980) & $0.34(0.13,0.83)$ & $6 / 223$ & $17 / 212$ & 17.24 \\
\hline Haines et al (1982) & $0.45(0.09,2.15)$ & $2 / 35$ & $5 / 39$ & 5.77 \\
\hline Odio et al (1984) & $0.71(0.19,2.71)$ & $3 / 18$ & $4 / 17$ & 7.95 \\
\hline Overall $(I-s q u a r e d=0.0 \%, p=0.958)$ & $0.55(0.38,0.81)$ & $38 / 643$ & $72 / 674$ & 100.00 \\
\hline
\end{tabular}

FIG. 2. Preoperative antibiotics forest plot for all studies in the meta-analysis.

viously entered into the trial. After stratification, patients were then randomized into treatment or control groups by using a block randomization schema of 4 patients at a time for a given stratum. Patients were monitored for a minimum of 2 years; and the clinicians assessing the patients and the microbiologists examining the specimens were both blinded to which treatment had been received. Patients who received antibiotics had an infection rate of $12 \%$, whereas those who received placebo had an infection rate of $19 \%$. With respect to all surgical procedures (n $=300$ ), the rates of infection were 9\% (14 of 155) and 15\% (22 of 145) for the antibiotic-treated and control groups, respectively. The trial was terminated early because the rates of infection in both groups were substantially higher than the rates of infection prior to the start of the study. No statistically significant difference in rates of infection was found between the two groups evaluated.

The other 3 Class I studies also found no difference in rates of infection. Wang et al..$^{40}$ performed a randomized, double-blind, placebo-controlled study with intravenous sulfamethoxazole and trimethoprim $(25 \mathrm{mg} / \mathrm{kg}$ sulfamethoxazole and $5 \mathrm{mg} / \mathrm{kg}$ trimethoprim given within 1 hour of surgery and then 8 and 16 hours postoperatively) in 120 patients who underwent ventriculoperitoneal (VP) shunt surgery. Patients were not stratified into subsets, and the mean follow-up was 11 months. The incidence of infection was virtually the same in the antibiotic-treated group (7.3\% [4 of 55]) and the control group (7.7\% [5 of 65]). Although the authors concluded that the results of their study did not support the use of prophylactic antibiotics, the low rate and small sample size may have obscured a true difference between the groups (Type II error).

Rieder et al. ${ }^{30}$ reported their results from another double-blind, placebo-controlled RCT in which cephalothin $(25 \mathrm{mg} / \mathrm{kg}$ cephalothin administered prior to incision followed by 3 postoperative doses every 6 hours) was used in 63 patients undergoing elective VP shunt insertion. Patients were not stratified to subsets, and follow-up was limited to 3 months. The infection rate was $6 \%$ (2 of 32) in the treatment group and 10\% (3 of 31) in the placebo group, a difference that was not significant. This study was also limited by the small sample size and the possibility of a Type II error. The final RCT that met our inclusion criteria was conducted by Haines and Taylor. ${ }^{20}$ This was a double-blind, placebo-controlled study of methicillin $(12.5 \mathrm{mg} / \mathrm{kg}$ every 6 hours administered 6 hours prior to surgery, at induction of anesthesia, and for 72 hours postoperatively) in 74 patients who underwent elective VP shunt placement. Thirty-five patients were in the methicillin group and 39 were in the placebo group. The methicillin group had more previous shunt infections and intercurrent infections than the placebo group, but 


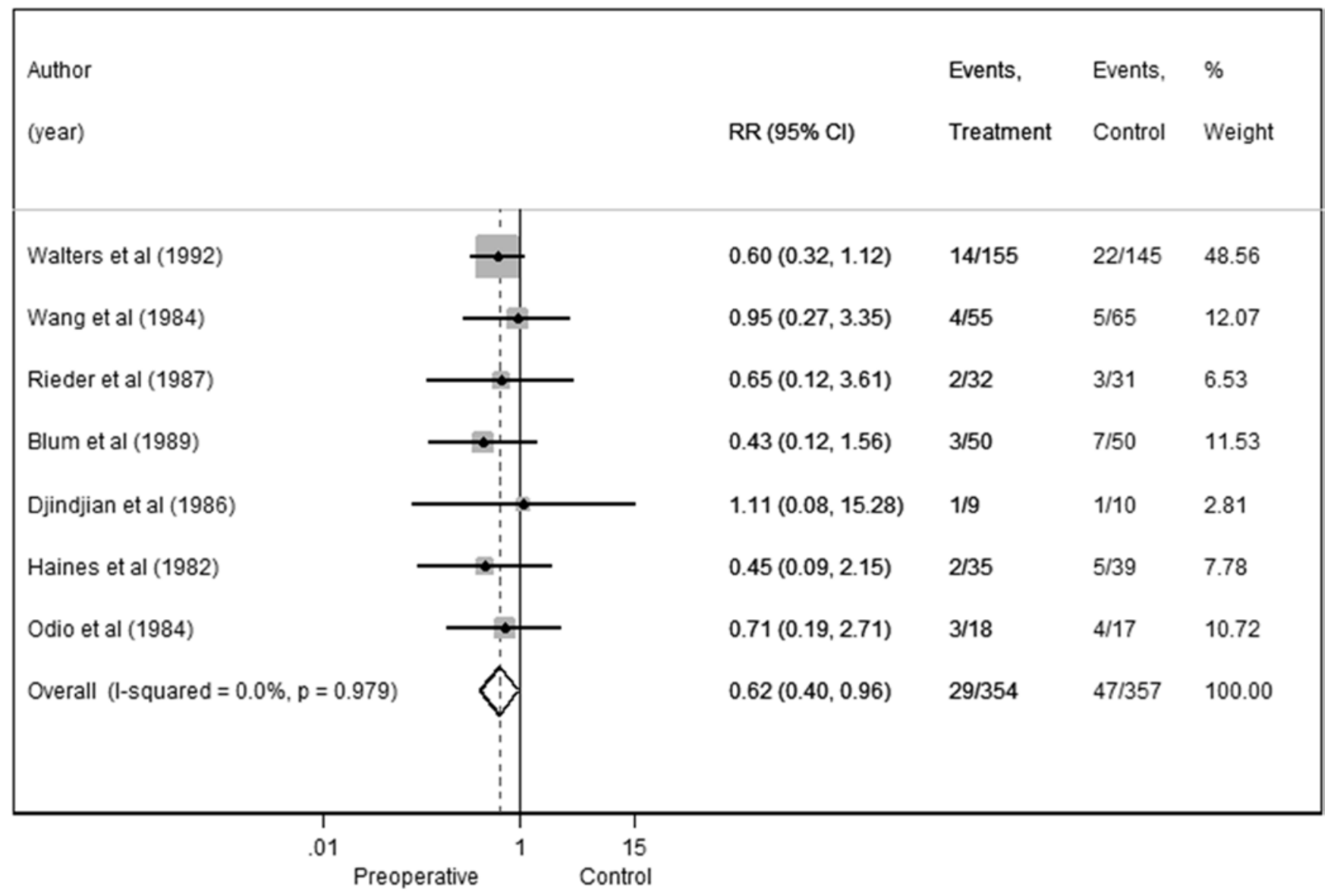

FIG. 3. Preoperative antibiotics forest plot for RCTs in the meta-analysis.

the placebo group had more shunt revisions. The mean follow-up was 6 months. The infection rate was 5.7\% (2 of 35 ) for the methicillin group and $12.8 \%$ (5 of 39) for the placebo group, a nonsignificant difference.

Our search also identified 2 retrospective cohort observational studies (Class III). Ajir et al. ${ }^{1}$ retrospectively analyzed the cases of 171 patients who underwent VP shunt procedures over a 6-year period. One hundred five patients did not receive antibiotics; 66 received methicillin $(50 \mathrm{mg} / \mathrm{kg})$ after induction of anesthesia and before skin incision. Interestingly, follow-up was limited to a maximum of 6 weeks after surgery. The study stratified patients into those in whom a new shunt was placed and those who received shunt revision. The infection rate was $4.5 \%$ (3 of 66 ) in the treatment group, with all infections arising in the new shunt placement subset. The infection rate was $7.6 \%$ (8 of 105) in the control group, with an equal number of infections $(n=4)$ in each of the subsets. Although methicillin seemed to prevent infections only in cases of shunt revision surgery, the overall difference in infection rates was statistically significant, and the authors concluded that a single bolus of methicillin was warranted for shunt surgery.

In another retrospective study, McCullough and colleagues ${ }^{26}$ evaluated 257 infants and children who underwent 435 shunt operations at some point during a 9.5 -year period. The authors compared 212 procedures in the first 4 years, during which patients did not receive preopera- tive antibiotics, and 223 procedures in the next 5.5 years, in which patients received preoperative methicillin (25 $\mathrm{mg} / \mathrm{kg}$ with 1 dose before transport to the operating room, 1 dose after exposing the shunt or cannulating the ventricle, and 6 postoperative doses every 6 hours). Patients were not stratified, and the length of follow-up was not reported. The infection rates were $2.7 \%$ (6 of 223) in the treatment group and 8\% (17 of 212) in the control group, a statistically significant protective benefit.

\section{Meta-Analysis Results}

There were 674 shunt operations without prophylactic antibiotics and 72 infections, yielding a pooled infection rate of $10.7 \%$. In the treatment groups, there were 38 infections associated with 643 operations, for an overall infection rate of $5.9 \%$. Thus, the absolute and relative risk reductions were $4.8 \%$ and $44.9 \%$, respectively. The overall RR was 0.55 (95\% CI 0.38-0.81), indicating a reduction in the risk of shunt infection with administration of prophylactic preoperative antibiotics (Fig. 2). No significant heterogeneity was detected $\left(\mathrm{I}^{2}=0.0 \%\right)$.

\section{Sensitivity Analysis}

We conducted a sensitivity analysis in which we examined only the 7 RCTs; the overall RR was 0.62 (95\% CI 0.40-0.96) with no heterogeneity observed $\left(\mathrm{I}^{2}=0.0 \%\right)$ 


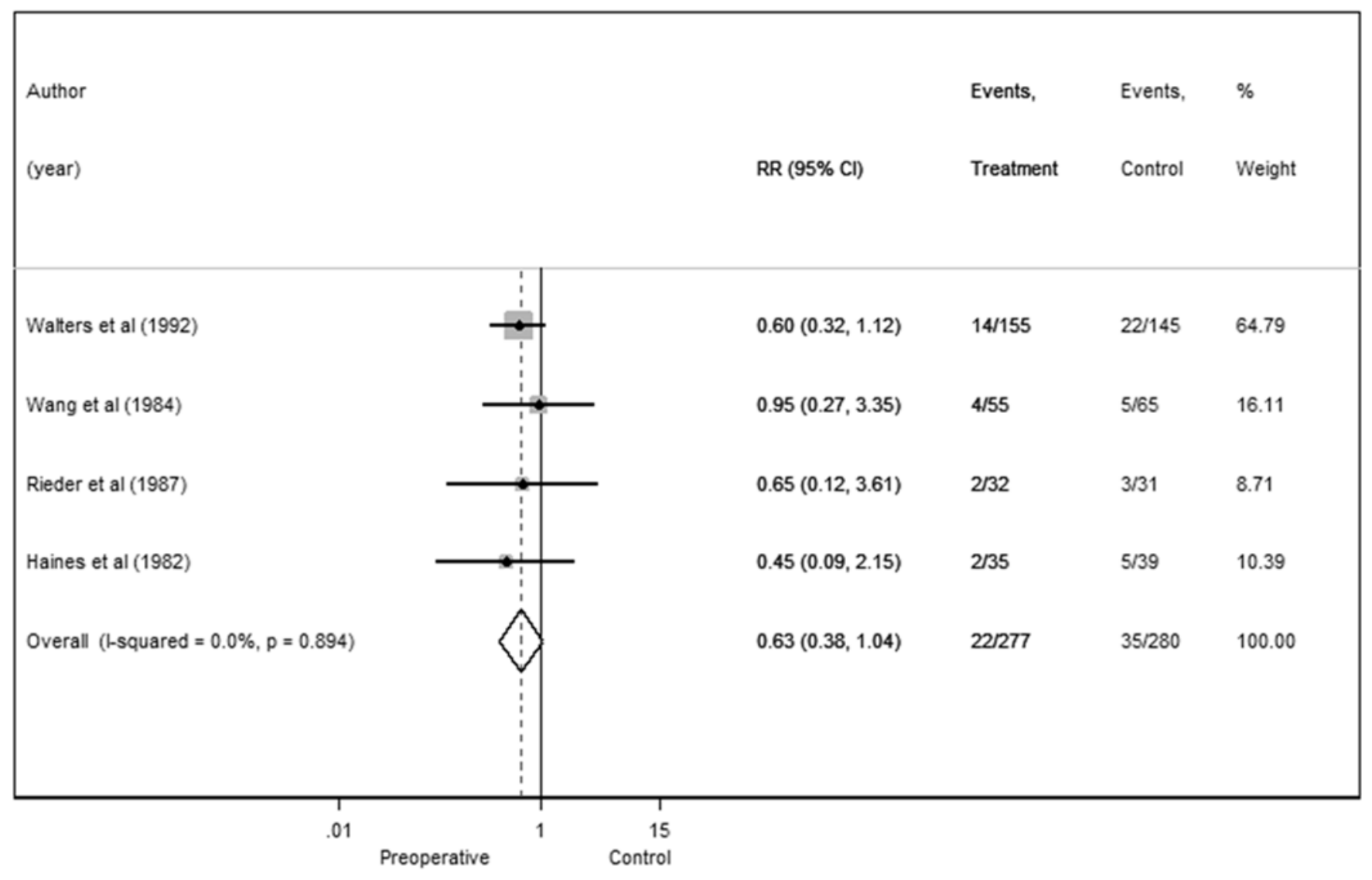

FIG. 4. Preoperative antibiotics forest plot for higher-quality RCTs.

(Fig. 3). Next, we examined just the 4 superior RCTs by performing a sensitivity analysis, and although the risk ratio remained protective, it was no longer statistically significant $(\mathrm{RR}=0.63 ; 95 \% \mathrm{CI} 0.38-1.04)$ (Fig. 4). The test of heterogeneity remained nonsignificant $\left(\mathrm{I}^{2}=0.0 \%\right)$.

\section{Conclusions}

RECOMMENDATION: The use of preoperative antibiotic agents can be recommended to prevent shunt infection in patients with hydrocephalus. It was only by combining the results of the various underpowered studies (metaanalysis) that the use of preoperative antibiotics for shunt surgery in children was shown to lower the risk of shunt infection. Strength of Recommendation: Level II, moderate degree of clinical certainty.

Given the available literature that met our inclusion criteria, the use of preoperative antibiotics for shunt surgery in children has not been shown to reduce the risk of developing a shunt infection. Nine trials, including 7 randomized controlled trials (RCTs), were critically evaluated. There were significant limitations and methodological flaws within the trials, most notably the potential to commit a Type II error (that is, failing to reject a false null hypothesis or, in other words, failing to detect a true therapeutic effect) because of inadequate power among the trials. Therefore, we conducted a meta-analysis to overcome the lack of power within many of the trials. Only with the meta-analysis did we demonstrate a protective benefit of preoperative antibiotics. This held true when we evaluated only the RCTs $(n=7)$, but lacked statistical significance when only the higher-quality RCTs $(n=4)$ were analyzed. The results of this systematic review and meta-analysis are, however, unlikely to spur further investigative trials within the United States, as the unwillingness of pediatric neurosurgeons to withhold prophylactic antibiotics from patients receiving shunts would be a monumental and insurmountable barrier (that is, a lack of clinical equipoise).

\section{Acknowledgments}

We acknowledge the American Association of Neurological Surgeons (AANS)/Congress of Neurological Surgeons (CNS) Joint Guidelines Committee for the members' reviews, comments, and suggestions; Laura Mitchell, Guidelines Project Manager for the CNS, for her contributions; Pamela Shaw, research librarian, for her assistance with the literature searches; Kevin Boyer for his assistance with data analysis; and Sue Ann Kawecki and Kristin Kraus, M.Sc., for their assistance with editing.

\section{Disclosure}

The systematic review and evidence-based guidelines were funded exclusively by the CNS and AANS Pediatric Section, which received no funding from outside commercial sources to support the development of this document. 
Conflict(s) of Interest: None. All Task Force members declared any potential conflicts of interest prior to beginning work on this evidence review.

Author contributions to the study and manuscript preparation include the following. Conception and design: AANS/CNS Joint Section on Pediatrics. Acquisition of data: all authors. Analysis and interpretation of data: all authors. Drafting the article: Klimo. Critically revising the article: all authors. Reviewed submitted version of manuscript: all authors. Approved the final version of the manuscript on behalf of all authors: Flannery. Statistical analysis: all authors. Administrative/technical/material support: all authors. Study supervision: Flannery.

\section{References}

1. Ajir F, Levin AB, Duff TA: Effect of prophylactic methicillin on cerebrospinal fluid shunt infections in children. Neurosurgery 9:6-8, 1981

2. Arnaboldi L: Antimicrobial prophylaxis with ceftriaxone in neurosurgical procedures. A prospective study of 100 patients undergoing shunt operations. Chemotherapy 42:384-390, 1996

3. Attenello FJ, Garces-Ambrossi GL, Zaidi HA, Sciubba DM, Jallo GI: Hospital costs associated with shunt infections in patients receiving antibiotic-impregnated shunt catheters versus standard shunt catheters. Neurosurgery 66:284-289, 2010

4. Barker FG II: Efficacy of prophylactic antibiotic therapy in spinal surgery: a meta-analysis. Neurosurgery 51:391-401, 2002

5. Barker FG II: Efficacy of prophylactic antibiotics against meningitis after craniotomy: a meta-analysis. Neurosurgery 60:887-894, 2007

6. Barker FG II: Efficacy of prophylactic antibiotics for craniotomy: a meta-analysis. Neurosurgery 35:484-492, 1994

7. Bayston R: Antibiotic prophylaxis in shunt surgery. Dev Med Child Neurol Suppl 17:99-103, 1975

8. Bayston R, Bannister C, Boston V, Burman R, Burns B, Cooke F, et al: A prospective randomised controlled trial of antimicrobial prophylaxis in hydrocephalus shunt surgery. $\mathbf{Z}$ Kinderchir 45 (Suppl 1):5-7, 1990

9. Biyani N, Grisaru-Soen G, Steinbok P, Sgouros S, Constantini S: Prophylactic antibiotics in pediatric shunt surgery. Childs Nerv Syst 22:1465-1471, 2006

10. Blomstedt GC: Results of trimethoprim-sulfamethoxazole prophylaxis in ventriculostomy and shunting procedures. A double-blind randomized trial. J Neurosurg 62:694-697, 1985

11. Blum J, Schwarz M, Voth D: Antibiotic single-dose prophylaxis of shunt infections. Neurosurg Rev 12:239-244, 1989

12. Bullock R, van Dellen JR, Ketelbey W, Reinach SG: A doubleblind placebo-controlled trial of perioperative prophylactic antibiotics for elective neurosurgery. J Neurosurg 69:687691, 1988

13. Chadduck W, Adametz J: Incidence of seizures in patients with myelomeningocele: a multifactorial analysis. Surg Neurol 30:281-285, 1988

14. Crowther M, Lim W, Crowther MA: Systematic review and meta-analysis methodology. Blood 116:3140-3146, 2010

15. Darouiche RO: Treatment of infections associated with surgical implants. N Engl J Med 350:1422-1429, 2004

16. Deeks JJ, Higgins JPT, Altman DG (eds): Chapter 9: Analysing data and undertaking meta-analyses, in Higgins JPT, Green S (eds): Cochrane Handbook for Systematic Reviews of Interventions, version 5.1.0. The Cochrane Collaboration, 2011

17. DerSimonian R, Laird N: Meta-analysis in clinical trials. Control Clin Trials 7:177-188, 1986

18. Djindjian M, Fevrier MJ, Otterbein G, Soussy JC: Oxacillin prophylaxis in cerebrospinal fluid shunt procedures: results of a randomized open study in 60 hydrocephalic patients. Surg Neurol 25:178-180, 1986

19. George R, Leibrock L, Epstein M: Long-term analysis of cerebrospinal fluid shunt infections. A 25-year experience. J Neurosurg 51:804-811, 1979

20. Haines SJ, Taylor F: Prophylactic methicillin for shunt operations: effects on incidence of shunt malfunction and infection. Childs Brain 9:10-22, 1982

21. Haines SJ, Walters BC: Antibiotic prophylaxis for cerebrospinal fluid shunts: a metanalysis. Neurosurgery 34:87-92, 1994

22. Jamjoom AB, Mohammed AA, al-Boukai A, Jamjoom ZA, Rahman N, Jamjoom HT: Multiloculated hydrocephalus related to cerebrospinal fluid shunt infection. Acta Neurochir (Wien) 138:714-719, 1996

23. Kestle JR, Hoffman HJ, Soloniuk D, Humphreys RP, Drake JM, Hendrick EB: A concerted effort to prevent shunt infection. Childs Nerv Syst 9:163-165, 1993

24. Langley JM, LeBlanc JC, Drake J, Milner R: Efficacy of antimicrobial prophylaxis in placement of cerebrospinal fluid shunts: meta-analysis. Clin Infect Dis 17:98-103, 1993

25. Mapstone TB, Rekate HL, Nulsen FE, Dixon MS Jr, Glaser N, Jaffe M: Relationship of CSF shunting and IQ in children with myelomeningocele: a retrospective analysis. Childs Brain 11:112-118, 1984

26. McCullough DC, Kane JG, Harleman G, Wells M: Antibiotic prophylaxis in ventricular shunt surgery. II. Antibiotic concentrations in cerebrospinal fluid. Childs Brain 7:190-194, 1980

27. Odio C, Mohs E, Sklar FH, Nelson JD, McCracken GH Jr: Adverse reactions to vancomycin used as prophylaxis for CSF shunt procedures. Am J Dis Child 138:17-19, 1984

28. Prusseit J, Simon M, von der Brelie C, Heep A, Molitor E, Volz S, et al: Epidemiology, prevention and management of VP shunt infections in children. Pediatr Neurosurg 45:325336, 2009

29. Ratilal B, Costa J, Sampaio C: Antibiotic prophylaxis for surgical introduction of intracranial ventricular shunts: a systematic review. J Neurosurg Pediatr 1:48-56, 2008

30. Rieder MJ, Frewen TC, Del Maestro RF, Coyle A, Lovell S: The effect of cephalothin prophylaxis on postoperative ventriculoperitoneal shunt infections. CMAJ 136:935-938, 1987

31. Schmidt K, Gjerris F, Osgaard O, Hvidberg EF, Kristiansen JE, Dahlerup B, et al: Antibiotic prophylaxis in cerebrospinal fluid shunting: a prospective randomized trial in 152 hydrocephalic patients. Neurosurgery 17:1-5, 1985

32. Schoenbaum SC, Gardner P, Shillito J: Infections of cerebrospinal fluid shunts: epidemiology, clinical manifestations, and therapy. J Infect Dis 131:543-552, 1975

33. Simon TD, Hall M, Dean JM, Kestle JR, Riva-Cambrin J: Reinfection following initial cerebrospinal fluid shunt infection. Clinical article. J Neurosurg Pediatr 6:277-285, 2010

34. Simon TD, Hall M, Riva-Cambrin J, Albert JE, Jeffries HE, Lafleur B, et al: Infection rates following initial cerebrospinal fluid shunt placement across pediatric hospitals in the United States. Clinical article. J Neurosurg Pediatr 4:156-165, 2009

35. Simon TD, Riva-Cambrin J, Srivastava R, Bratton SL, Dean JM, Kestle JR: Hospital care for children with hydrocephalus in the United States: utilization, charges, comorbidities, and deaths. J Neurosurg Pediatr 1:131-137, 2008

36. Simon TD, Whitlock KB, Riva-Cambrin J, Kestle JR, Rosenfeld M, Dean JM, et al: Revision surgeries are associated with significant increased risk of subsequent cerebrospinal fluid shunt infection. Pediatr Infect Dis J 31:551-556, 2012

37. Vanaclocha V, Sáiz-Sapena N, Leiva J: Shunt malfunction in relation to shunt infection. Acta Neurochir (Wien) 138:829_ 834, 1996

38. Viano JC, Tregnaghi M, Casagnas M, Suárez JC: Valvular infections in patients with hydrocephalus: preventive aspects. Childs Nerv Syst 6:397-399, 1990 
39. Walters BC, Goumnerova L, Hoffman HJ, Hendrick EB, Humphreys RP, Levinton C: A randomized controlled trial of perioperative rifampin/trimethoprim in cerebrospinal fluid shunt surgery. Childs Nerv Syst 8:253-257, 1992

40. Wang EE, Prober CG, Hendrick BE, Hoffman HJ, Humphreys RP: Prophylactic sulfamethoxazole and trimethoprim in ventriculoperitoneal shunt surgery. A double-blind, randomized, placebo-controlled trial. JAMA 251:1174-1177, 1984

41. Weiss SR, Raskind R: Further experience with the ventriculoperitoneal shunt. Prophylactic antibiotics. Int Surg 53:300303, 1970

42. Wong JM, Ziewacz JE, Ho AL, Panchmatia JR, Bader AM, Garton HJ, et al: Patterns in neurosurgical adverse events: cerebrospinal fluid shunt surgery. Neurosurg Focus 33(5):E13, 2012

43. Young RF, Lawner PM: Perioperative antibiotic prophylaxis for prevention of postoperative neurosurgical infections. A randomized clinical trial. J Neurosurg 66:701-705, 1987

44. Yu HC, Patterson RH Jr: Prophylactic antimicrobial agents after ventriculoatriostomy for hydrocephalus. J Pediatr Surg 8:881-885, 1973

Manuscript submitted June 25, 2014.

Accepted July 7, 2014.

Please include this information when citing this paper: DOI: 10.3171/2014.7.PEDS14326.

Address correspondence to: Ann Marie Flannery, M.D., Department of Neurological Surgery, Saint Louis University, 3565 Vista Ave., St. Louis, MO 63110. email: flanneam@slu.edu. 